\title{
Toekomstige risico's voor de nationale veiligheid
}

\section{Minke Meijnders, Leendert Gooijer en Hanneke Duijnhoven*}

Wat zijn de komende jaren de grootste bedreigingen voor onze nationale veiligheid? Welke langetermijnontwikkelingen gaan onze veiligheid op den duur raken? Hoe hangen risico's met elkaar samen? Het Analistennetwerk Nationale Veiligheid (ANV) houdt zich al lange tijd bezig met dergelijke vragen. In dit artikel lichten we toe hoe we tot beantwoording van deze vragen komen. We gaan eerst kort in op de vraag wat het ANV is en welke typen studies we leveren. Vervolgens gaan we in op de twee belangrijkste producten van het ANV: de risicoanalyse voor de nationale veiligheid en de Horizonscan Nationale Veiligheid. Welk doel hebben deze studies? Welke methodes worden toegepast om de toekomstige risico's en de relevante ontwikkelingen inzichtelijk te maken? Welke inzichten leveren de studies op als het gaat om nationale veiligheid? En wat is het belang van dergelijke studies?

\section{Het ANV: toekomstverkenner voor de nationale veiligheid}

Het ANV is sinds 2011 verantwoordelijk voor het leveren van onafhankelijke analyses ten behoeve van de nationale veiligheid. Dit doen we hoofdzakelijk in opdracht van de Nationaal Coördinator Terrorismebestrijding en Veiligheid (NCTV). De kern van het netwerk wordt gevormd door zes kennisinstellingen: RIVM, TNO, AIVD, WODC, Instituut Clingendael en Institute of Social Studies (ISS). Door de verscheidenheid aan expertises is het netwerk in staat een multidisciplinaire blik op de nationale veiligheid te geven. Naast deze kern bestaat het ANV uit een ruime 'ring' van instellingen, overheidsdien-

* Dr. M. Meijnders was tot voor kort Research Fellow bij Instituut Clingendael en in die functie betrokken bij het ANV. Ir. Leendert Gooijer is programmacoördinator nationale veiligheid bij het RIVM en tevens Algemeen Secretaris van het ANV. Dr. Hanneke Duijnhoven is Senior scientist nationale veiligheid bij TNO en in die functie betrokken bij het ANV. 
sten, veiligheidsregio's, bedrijven en onderzoeksbureaus, waarvan regelmatig experts worden betrokken bij specifieke studies of activiteiten van het ANV.

Die multidisciplinaire aanpak van het ANV is zeker nodig bij studies gericht op de nationale veiligheid. Nationale veiligheid is een enorm breed onderwerp en gaat over de risico's van verschillende rampen, dreigingen en crises die onze samenleving kunnen ontwrichten. Overstromingen, terroristische aanslagen, uitbraak van ziekten, cyberaanvallen, het zijn slechts enkele voorbeelden van onderwerpen die relevant zijn voor de nationale veiligheid.

De voornaamste taak van het ANV is input leveren voor de Nationale Veiligheidsstrategie van de Nederlandse overheid. Sinds de oprichting van het ANV ligt de primaire focus op de uitvoering van de nationale risicobeoordeling, die als doel heeft voor beleidsmakers inzichtelijk te maken wat de belangrijkste (toekomstige) risico's zijn die onze samenleving kunnen ontwrichten. Tot 2014 produceerde het ANV jaarlijks een Nationale Risicobeoordeling (NRB), waarin steeds een aantal risico's centraal stonden. In 2016 is de eerste integrale versie van de risicobeoordeling uitgebracht: het Nationaal Veiligheidsprofiel, met daarin niet alleen een overzicht van de belangrijkste risico's, maar ook meer aandacht voor de context van de risico's en dreigingen en langetermijntrends (ANV 2016). In maart 2019 is de eerste Geïntegreerde Risicoanalyse Nationale Veiligheid (ANV 2019a) verschenen, waarin ten opzichte van eerdere risicobeoordelingen meer aandacht wordt besteed aan de samenhang tussen interne en externe risico's. Daarnaast produceren we ook verschillende verdiepende studies, over thema's zoals de energietransitie of hybride conflictvoering. ${ }^{1}$ Ook voeren we zogenoemde challenges uit, een methode waarbij een kleine groep experts in een besloten setting een reeks toekomstscenario's ontwikkelt, bijvoorbeeld over thema's als economische veiligheid of cyberveiligheid. Recent is een nieuw type analyse toegevoegd aan het vaste repertoire van het ANV; de Horizonscan Nationale Veiligheid (ANV 2018). Dit is een aanvulling op de reguliere risicoanalyse en heeft

1 Met hybride operaties wordt bedoeld het geïntegreerd gebruik van conventionele en nonconventionele middelen, open en heimelijke activiteiten en de inzet van militaire, paramilitaire en civiele actoren en middelen om ambiguïteit te creëren en kwetsbaarheden van de tegenstander te raken om geopolitieke en strategische doelstellingen te bereiken. Beïnvloeding en misleiding door gemanipuleerde informatievoorziening maken een belangrijk deel uit van hybride tactieken. Hybride operaties kunnen zich voor een groot deel voordoen onder de drempel van oorlogvoering. 
als doel periodiek trends en ontwikkelingen te duiden die van invloed zijn op het risicolandschap.

In het vervolg van dit artikel gaan we eerst in op de meest recente risicoanalyse die het ANV heeft gepubliceerd en de vaste methodiek die daarbij wordt gehanteerd. Vervolgens zoomen we in op de Horizonscan Nationale Veiligheid en de daarbij gehanteerde foresightmethode.

\section{De belangrijkste risico's voor de nationale veiligheid}

De meest recente Geïntegreerde Risicoanalyse Nationale Veiligheid van het ANV (ANV 2019a) is opgesteld na het besluit van het kabinet in 2018 om een meerjarige Nationale Veiligheidsstrategie te ontwikkelen. De risicoanalyse geeft een all hazard overzicht van de mogelijke rampen, crises en dreigingen die de maatschappij zouden kunnen ontwrichten. Dit gaat zowel over safety- als security-risico's. Denk daarbij aan natuurrampen, dreigingen voor de gezondheid, maar ook aan financieel-economische risico's, cyberdreigingen en risico's op het vlak van internationale vrede en veiligheid. Er worden in totaal negen verschillende dreigingsthema's bekeken (zie tabel 1).

\section{Tabel 1 Beschouwde dreigingsthema's in de risicoanalyse} (in willekeurige volgorde)

\section{Dreigingsthema's}

Bedreigingen gezondheid en milieu

Natuurrampen

Verstoring vitale infrastructuur

Zware ongevallen

Cyberdreigingen

Ondermijning democratische rechtsstaat

Gewelddadig extremisme en terrorisme

Financieel-economische bedreigingen

Bedreigingen internationale vrede \& veiligheid

Voor de risicobeoordelingen van het ANV wordt gebruikgemaakt van een beproefde methodiek (ANV 2019b). Deze nationale risicobeoordelingsmethodiek is in 2007 ontwikkeld door de voorloper van het ANV (de werkgroep Nationale Risicobeoordeling) in het kader van de Stra- 
tegie Nationale Veiligheid die destijds werd gelanceerd door het kabinet. De basis van de methodiek (een multi-criteria decision analysis (MCDA) van impact en waarschijnlijkheid) wordt tot op de dag van vandaag gebruikt. In de loop der jaren is de methode op een aantal punten doorontwikkeld, bijvoorbeeld door de operationalisatie van verschillende onderdelen aan te passen en door het toevoegen van enkele impactcriteria om aan te blijven sluiten bij de dynamische context van risico's en dreigingen. Internationaal gezien was Nederland met de ontwikkeling van de methodiek in de context van de Strategie Nationale Veiligheid, samen met het Verenigd Koninkrijk, een van de eerste landen die op deze wijze een nationale risicobeoordelingsaanpak lanceerde (ANV 2019b). Inmiddels bestaat er Europees beleid op dit gebied en dienen alle Europese lidstaten periodiek een nationale risicobeoordeling uit te voeren [OECD 2009; OECD 2017].

Voor de verschillende type risico's worden fictieve scenario's ontwikkeld, denk bijvoorbeeld aan een militaire escalatie in een NAVO-lidstaat, een ernstige grieppandemie, een dijkdoorbraak in een deel van de Randstad of een blokkade van een zeestraat. Deze scenario's worden beoordeeld door een multidisciplinaire groep van experts op hun impact en waarschijnlijkheid tijdens expertsessies. Bij impact draait het om de mogelijke impact die het scenario kan hebben op de zes nationale veiligheidsbelangen: territoriale, fysieke, ecologische en economische veiligheid, sociale en politieke stabiliteit en de internationale rechtsorde (zie tabel 2). Dit laatste belang is recent door het ANV ontwikkeld en toegevoegd aan de set nationale veiligheidsbelangen.

Om de impact concreet en meetbaar te maken, zijn de nationale veiligheidsbelangen uitgewerkt in impactcriteria (ANV 2019b). De mate van ernst wordt ingedeeld in vijf verschillende klassen (gebruikmakend van een logaritmische schaal), variërend van beperkt tot catastrofaal. Om een beeld te geven: bij fysieke veiligheid is een van de criteria het aantal dodelijke slachtoffers dat kan vallen bij een ramp of crisis, van beperkt (minder dan 10) tot catastrofaal (meer dan 10.000). Voor minder goed objectiveerbare criteria, bijvoorbeeld maatschappelijke onrust of aantasting van multilaterale instituties, wordt per klasse beschreven wat de ernst van de situatie is. 


\section{Tabel 2 De zes nationale veiligheidsbelangen}

\begin{tabular}{|c|c|}
\hline Territoriale veiligheid & $\begin{array}{l}\text { Het ongestoord functioneren van Nederland en } \\
\text { haar EU- en NAVO-bondgenoten als onafhan- } \\
\text { kelijke staten in brede zin, dan wel de territori- } \\
\text { ale veiligheid in enge zin. }\end{array}$ \\
\hline Fysieke veiligheid & $\begin{array}{l}\text { Het ongestoord functioneren van de mens in } \\
\text { Nederland en zijn omgeving. }\end{array}$ \\
\hline Economische veiligheid & $\begin{array}{l}\text { Het ongestoord functioneren van Nederland } \\
\text { als een effectieve en efficiënte economie. }\end{array}$ \\
\hline Ecologische veiligheid & $\begin{array}{l}\text { Het ongestoord voortbestaan van de } \\
\text { natuurlijke leefomgeving in en nabij Neder- } \\
\text { land. }\end{array}$ \\
\hline Sociale en politieke stabiliteit & $\begin{array}{l}\text { Het ongestoorde voortbestaan van een maat- } \\
\text { schappelijk klimaat waarin individuen onge- } \\
\text { stoord kunnen functioneren en groepen } \\
\text { mensen goed met elkaar kunnen samenleven } \\
\text { binnen de verworvenheden van de Neder- } \\
\text { landse democratische rechtsstaat en daarin } \\
\text { gedeelde waarden. }\end{array}$ \\
\hline Internationale rechtsorde & $\begin{array}{l}\text { Het goed functioneren van het internationale } \\
\text { stelsel van normen en afspraken, gericht op } \\
\text { het bevorderen van de internationale vrede en } \\
\text { veiligheid. }\end{array}$ \\
\hline
\end{tabular}

Alle scenario's worden door experts uit het netwerk op deze wijze beoordeeld op hun mate van impact en waarschijnlijkheid. Daarmee worden de risico's onderling vergelijkbaar. In de risicoanalyse richten we ons op de grootste risico's voor de komende vijf jaar.

Wat zijn volgens het ANV de belangrijkste risico's voor de nationale veiligheid voor de komende vijf jaar? Deze vraag wordt vanuit verschillende perspectieven beantwoord. Allereerst beschouwt het ANV de risico's vanuit de impact die ze kunnen hebben op de nationale veiligheidsbelangen. Vanuit dit perspectief zijn het met name de risico's met een fysieke impact die opvallen. Een overstroming vanuit zee is daarbij een van de meest impactvolle scenario's, dit zou kunnen leiden tot langdurige uitval van vitale infrastructuur, waarbij het dagelijks leven ernstig verstoord raakt, grote aantallen slachtoffers vallen en er een gebrek aan primaire levensbehoeften kan ontstaan. Tel daarbij op de economische schade en het feit dat een deel van het grondgebied tijdelijk niet gebruikt kan worden.

Een tweede perspectief waarop het ANV de risico's beschouwt, is door te kijken welke risico's het meest waarschijnlijk optreden. Opvallend is dat de risico's die de hoogte impact hebben op de nationale veiligheid, over het algemeen juist een lage waarschijnlijkheid van optreden 
hebben. ${ }^{2}$ De risico's die een hoge mate van waarschijnlijkheid hebben, zijn typen risico's die moedwillig worden veroorzaakt door een bepaalde actor. Denk daarbij aan cyberdreigingen, ondermijning en ongewenste beïnvloeding door buitenlandse staten (zoals Rusland, China, Turkije). Als we deze twee perspectieven combineren, impact en waarschijnlijkheid, komen negen risico's voor de nationale veiligheid naar voren (zie tabel 3).

\section{Tabel 3 Belangrijkste risico's voor de nationale veiligheid op basis van impact en waarschijnlijkheid}

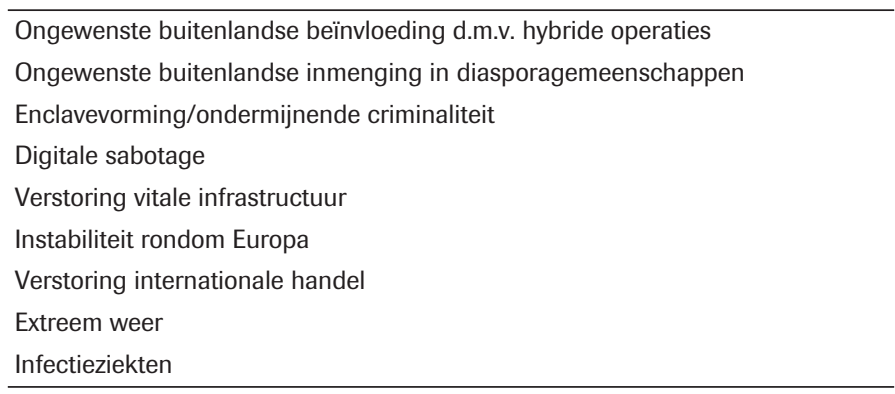

Een dergelijk overzicht kan de overheid helpen bij het prioriteren van beleid en capaciteiten. De achterliggende analyses geven de nuances weer als het gaat om de verwachte impact en waarschijnlijkheid. Neem bijvoorbeeld het eerste risico, het toenemende risico op ondermijning door statelijke actoren via onder meer hybride operaties. Hoewel de inzet van deze operaties niets nieuws is, is de schaal en frequentie waarop steeds assertiever wordende staten dit inzetten wel nieuw. Om inzicht te krijgen in het mogelijke effect van dergelijke operaties op de nationale veiligheid, heeft het ANV meerdere fictieve scenario's ontwikkeld rondom dit thema. Het eerste scenario richt zich op Rusland, het tweede op China. In het Rusland-scenario draait het voornamelijk om het gebruik van desinformatiecampagnes (bijv. rondom verkiezingen), propagandacampagnes en gerichte cyberaanvallen. Het doel van Rusland is het vergroten van zijn machtspositie, door democratische samenlevingen (inclusief waarden als vrije pers en de liberale rechtsorde) en instituties zoals de NAVO en de EU te 
ondermijnen en te verzwakken. In de impactbeoordeling van dit scenario komen de experts dan ook tot de conclusie dat Russische operaties met name de sociale en politieke stabiliteit, de digitale ruimte en de bondgenootschappelijke verbanden raken. In het China-scenario wordt duidelijk dat China's beïnvloedingsactiviteiten veelal via legale, voornamelijk economische kanalen gaan. China's strategie is veel meer gericht op de langere termijn, het wil zijn economische en politieke invloed de komende decennia vergroten. In het scenario wordt pas echt duidelijk hoe groot de invloed van China op den duur is, in een situatie waarin Europese lidstaten gedwongen worden een keus te maken tussen China en de VS. In de beoordeling van dit risico bezien de experts dan ook met name het effect op de economische belangen en de internationale rechtsorde. Beide scenario's zijn door de experts als waarschijnlijk ingeschat, er zijn zelfs nu aanwijzingen dat dit risico zich ook daadwerkelijk zal voordoen.

Juist door twee verschillende actoren te belichten, krijgen we inzicht in de verschillende doelen en tactieken van deze actoren, en hoe dit verschillend uitwerkt op onze nationale veiligheid. Tegelijkertijd laten deze scenario's ook zien dat de weging van risico's meer is dan de som van impact maal waarschijnlijkheid. Zo zien we dat sommige risico's (in het geval van China) een meer sluipend effect hebben, en zijn er duidelijk dwarsverbanden zichtbaar tussen de risico's. Zo maken hybride operaties handig gebruik van bestaande kwetsbaarheden in de samenleving (bijvoorbeeld in het maatschappelijk debat) en zorgt de toenemende digitalisering voor meer aangrijpingspunten voor hybride operaties. Neem daarbij ook in ogenschouw dat ook onze vitale infrastructuur steeds meer afhankelijk wordt van internet, en daarmee kwetsbaarder is voor ongewenste inmenging van buitenaf.

\section{Welke nieuwe dreigingen kunnen we verwachten?}

De risicoanalyses richten zich op risico's die zich de komende vijf jaar kunnen voordoen. Deze risico's ontstaan nooit in een vacuüm maar worden beïnvloed door allerlei lange(re)termijnontwikkelingen. Hoewel binnen de risicoanalyses kort wordt aangestipt welke lange(re)termijnontwikkelingen de risico's mogelijk kunnen beïnvloeden, is er behoefte om meer aandacht te schenken aan de context van de risico's en de het langeretermijnperspectief. De laatste jaren 
besteedt het ANV daarom meer aandacht aan deze 'megatrends'. Megatrends zijn ontwikkelingen die vaak langzaam gaan, maar die, als ze eenmaal zijn geformeerd, een fundamenteel en langdurig effect hebben. Denk bijvoorbeeld aan klimaatverandering of vergrijzing. In 2018 bracht het ANV voor het eerst een Horizonscan Nationale Veiligheid (ANV 2018) uit. Deze horizonscan richt zich met name op nieuwe ontwikkelingen die zich kunnen voordoen. De scan heeft als doel signalerend en agenderend te zijn voor de daaropvolgende risicoanalyse: wat zijn de belangrijkste ontwikkelingen die mogelijk van invloed zijn op de nationale veiligheid?

Horizonscanning is een foresight-methode. Het kent vele verschillende vormen, maar in essentie is het een techniek waarbij een grote hoeveelheid bronnen wordt gescand op nieuwe signalen die relevant kunnen zijn voor, in dit geval, de nationale veiligheid. Het is een methode die internationaal wordt erkend en gebruikt om beleidsprocessen te voeden en sturen. ${ }^{3}$

De Horizonscan Nationale Veiligheid is een brede scan op vijf vlakken: internationale politiek, internationale economie, demografisch-maatschappelijke ontwikkelingen en technologie. ${ }^{4}$ Daarbinnen zijn bepaalde megatrends afgebakend, waarop de scan zich richt. Het ANV vraagt interne collega's en externe peers om mee te denken met deze afbakening: zijn dit daadwerkelijk de belangrijkste megatrends waarop het ANV zou moeten scannen? Als deze megatrends zijn vastgesteld, scant het ANV vervolgens op concrete manifestaties van deze megatrends, denk bijvoorbeeld aan spanningen tussen China en de VS als het gaat om de megatrend 'spanningen tussen grootmachten'. Hoe is het ANV te werk gegaan? De methode die als uitgangspunt is gebruikt, is die van Instituut Clingendael, die deze methode heeft ontwikkeld als onderdeel van zijn Strategic Foresight-programma (Instituut Clingendael 2018). Deze gaat uit van een structured expert basedbenadering. Dat wil zeggen dat de thematische deskundigheid van experts centraal staat, gecorrigeerd en gevalideerd door een proces van peer review en gebaseerd op een systematische scan van een grote

3 Bijvoorbeeld door de OESO, zie: https://www.oecd.org/site/schoolingfortomorrow knowledgebase/futuresthinking/overviewofmethodologies.htm

4 In veel toekomstverkenningen worden gewerkt met DESTEP, een indeling in zes categorieën factoren: demografische, economische, sociaal-culturele, technologische, ecologische en politiek-juridische. Deze factoren hebben veelal betrekking op drijvende krachten (niet op trends en processen) en de internationale dimensie ontbreekt. Daarom kiest het ANV voor een iets andere indeling. 
hoeveelheid relevante bronnen. Per thema en megatrends zijn er hubs of foreward thinking vastgesteld, plekken waar het meest wordt nagedacht over actuele, maar ook over toekomstgerichte onderwerpen. Bronnen op dit vlak zijn bijvoorbeeld conferentieagenda's van denktanks en onderzoeksinstituten, publicaties van toonaangevende nationale en internationale organisaties maar ook Twitter-feeds van gerenommeerde experts. Deze bronnenlijst wordt ook weer aangevuld en gevalideerd door collega's en peers. Vervolgens start het daadwerkelijk scannen van deze bronnen in kleine groepen van experts. Elke relevante ontwikkeling wordt gecodeerd door het team, middels een vastgesteld codeboek en bijbehorend template. Deze codering wordt altijd gecontroleerd door de leiding van het scanteam. Deze scan levert in de eerste ronde een lange lijst op van relevante ontwikkelingen voor de nationale veiligheid, de longlist. Vervolgens wordt aan de hand van een aantal criteria (verwachte impact op de nationale veiligheid, waarschijnlijkheid van optreden, maar ook in hoeverre de ontwikkeling nieuw is en onderbelicht op de beleidsagenda) een mediumlist opgesteld. Deze mediumlist wordt tot slot besproken tijdens een expertsessie, waarbij het ANV een beroep doet op experts in de brede 'ring' van experts. De experts bespreken de mediumlist, discussiëren over de mogelijke effecten voor de nationale veiligheid en vullen aan waar nodig. Deze discussies leiden tot een prioritering en soms tot identificering van nieuwe, of onderbelichte manifestaties. Uiteindelijk levert dit gestructureerde proces een beeld op van de belangrijkste ontwikkelingen die opdoemen aan de horizon van de Nederlandse nationale veiligheid.

In 2018 is er op een aantal megatrends gescand (zie tabel 4). De resultaten van deze scan worden uitgebreid besproken in het rapport, we beperken ons hier slechts tot een bespreking van de hoofdpunten. Binnen het thema internationale politiek springt de toenemende assertiviteit van Rusland en China in het oog, deze landen manifesteren zich nadrukkelijker op het wereldtoneel. Daarnaast nemen nucleaire spanningen toe, nu een aantal staten hun nucleaire arsenaal moderniseren of uitbreiden en ontwapeningsverdragen onder druk staan. Uit de scan volgt ook dat de trans-Atlantische band van karakter verandert en niet langer als vanzelfsprekend beschouwd mag worden. Er wordt tevens ingegaan op de politieke instabiliteit van de EU: we zien toenemende divergentie tussen lidstaten over Europese waarden, waarbij het project EU als geheel in twijfel wordt getrokken. De brexit 
is daarvan een duidelijk voorbeeld, maar ook de opkomst en populariteit van anti-Europese partijen. Tot slot gaat dit thema in op ontwikkelingen rondom terrorisme en het gevaar van salafistisch-jihadistische varianten van de politieke islam. IS zal in andere verschijningvormen blijven voortbestaan. Daarnaast moet rekening worden gehouden met terugkerende foreign terrorist fighters, waarbij vrouwen een aparte risicocategorie vormen.

\section{Tabel 4 Thema's en megatrends Horizonscan Nationale} Veiligheid 2018

\begin{tabular}{|c|c|c|c|c|}
\hline $\begin{array}{l}\text { Inter- } \\
\text { nationale } \\
\text { politiek }\end{array}$ & $\begin{array}{l}\text { Internationale } \\
\text { economie }\end{array}$ & Ecologie & $\begin{array}{l}\text { Demogra- } \\
\text { fisch- maat- } \\
\text { schappelijk }\end{array}$ & $\begin{array}{l}\text { Informatie- } \\
\text { technologie }\end{array}$ \\
\hline $\begin{array}{l}\text { Spanningen } \\
\text { tussen groot- } \\
\text { machten }\end{array}$ & $\begin{array}{l}\text { Herstructurering } \\
\text { mondiale finan- } \\
\text { cieel-economische } \\
\text { orde en nieuwe } \\
\text { netwerken }\end{array}$ & $\begin{array}{l}\text { Klimaat- } \\
\text { verandering }\end{array}$ & $\begin{array}{l}\text { Groeiende } \\
\text { kloof tussen } \\
\text { bevolkings- } \\
\text { groepen }\end{array}$ & Autonomie \\
\hline $\begin{array}{l}\text { Politieke insta- } \\
\text { biliteit EU }\end{array}$ & $\begin{array}{l}\text { Technologische } \\
\text { ontwikkelingen in } \\
\text { de financiële sec- } \\
\text { tor }\end{array}$ & Milieudruk & $\begin{array}{l}\text { Fluctuering } \\
\text { van vertrou- } \\
\text { wen in de } \\
\text { politiek en } \\
\text { instituties }\end{array}$ & Cognitie \\
\hline \multirow[t]{2}{*}{$\begin{array}{l}\text { Ont- } \\
\text { wikkelingen } \\
\text { terrorisme }\end{array}$} & $\begin{array}{l}\text { Economische } \\
\text { instabiliteit EU }\end{array}$ & $\begin{array}{l}\text { Biodiversiteit } \\
\text { en-massa }\end{array}$ & $\begin{array}{l}\text { Gevolgen van } \\
\text { toenemende } \\
\text { diversiteit } \\
\text { samenleving }\end{array}$ & $\begin{array}{l}\text { Verbonden- } \\
\text { heid / verwe- } \\
\text { venheid }\end{array}$ \\
\hline & & & & $\begin{array}{l}\text { Afhankelijk- } \\
\text { heid }\end{array}$ \\
\hline
\end{tabular}

De scan internationale economie is gericht op de veranderende economische orde. Er is een herschikking gaande waarvan de economische en veiligheidsconsequenties nog niet zijn uitgekristalliseerd. Hierbij komt sterk de nog onduidelijke rol van China naar voren: enerzijds omarmt het land delen van de huidige orde, maar tegelijkertijd stelt het ook de spelregels van de liberale marktorde ter discussie en probeert het deze naar zijn hand te zetten. Hoe China zijn groeiende invloed via grote infrastructuurprojecten (Belt and Road Initiative) en grootschalige investeringen uiteindelijk zal inzetten, en wat voor effect dat heeft op de eenheid van de EU, is vooralsnog onduidelijk. Ook wijst de scan op het gevaar van uitholling van de mondiale orde door het huidig beleid van protectionisme van de VS. De scan gaat daarnaast in op de economische instabiliteit binnen de EU, en wijst op 
risico's van de brexit maar ook op de instabiliteit van de eurozone. Een ander thema dat wordt aangestipt, zijn de risico's rondom technologische ontwikkelingen in de financiële sector, denk aan cryptovaluta. Deze digitale valuta's worden steeds populairder, maar internationale regelgeving hieromheen ontbreekt nog. Een ander risico is dat deze cryptovaluta's gebruikt worden voor witwassen en het financieren van terroristische activiteiten.

Binnen het thema 'demografisch-maatschappelijk' is er gescand op de groeiende kloof tussen bevolkingsgroepen. Deze kloof is zowel zichtbaar langs sociaal-culturele als sociaal-economische scheidslijnen. Zo is er bijvoorbeeld sprake van een duidelijke verharding van het (online) maatschappelijk debat. Het gebruik van sociale media en de zogenoemde media bubble kunnen de versnippering of 'parallellisering' van de maatschappij versterken, maar ook gevoelens van economische achterstelling dragen daaraan bij. Hoewel de Nederlandse maatschappij altijd al een bepaalde mate van versnippering kende, neemt deze de laatste jaren steeds grotere vormen aan. Daarnaast neemt de onvrede toe over de toegenomen diversiteit van de Nederlandse samenleving. De scan zoomt vervolgens in op de mate van vertrouwen in de politiek en instituties. Hoewel het vertrouwen in de instituten al jaren groot is en blijft, fluctueert de mate van vertrouwen in de personen die er werken. Dit verschilt overigens per subgroep in de samenleving, het vertrouwen in de media is bijvoorbeeld onder sommige groepen jongeren scherp afgenomen.

Het thema technologische ontwikkelingen focust specifiek op de razendsnelle ontwikkelingen binnen het terrein van informatietechnologie. Zo wordt aandacht gevraagd voor de potentiële risico's rondom artificial intelligence en machine learning. We zien dat er steeds meer gebruik wordt gemaakt van zelflerende systemen die zichzelf nieuwe taken en gedrag aanleren en op basis van die kennis zelfstandig beslissingen nemen. Als hierbij gebruik wordt gemaakt van biased informatie, kan het systeem vooringenomenheid ontwikkelen en op basis daarvan verkeerde beslissingen nemen. De scan is daarnaast gericht op onbeheersbaarheid en ongewenst gedrag van autonome systemen, denk aan zelfsturende auto's. De interactie van meerdere autonome systemen kan leiden tot ernstige verstoringen, bijvoorbeeld als ze niet afdoende op elkaar afgestemd zijn. Een extra risico is dat dergelijke systemen vaak afhankelijk zijn van het internet, wat de kans op (ongewenste) systeemovername groter maakt. Dit geldt in het 
algemeen voor de steeds grotere verbondenheid en verwevenheid van systemen en netwerken (hyperconnectedness). Tot slot wijst de scan op de steeds groter wordende afhankelijkheid van grote buitenlandse techbedrijven. Niet alleen is daardoor de governance moeilijk te regelen, maar leidt dit ertoe dat vitale digitale structuren in handen zijn van buitenlandse spelers.

Het laatste thema, ecologie, zoomt in op de effecten van klimaatverandering. Zoals ook vermeld in de geïntegreerde risicoanalyse, leidt de klimaatverandering tot opwarming van de aarde en tot extreem weer. Daarnaast hangt de opkomst van exoten samen met klimaatverandering. Planten en dieren uit zuidelijke regio's trekken meer richting het noorden, waardoor mensen, planten en dieren hier te maken kunnen krijgen met nieuwe infectieziekten. De scan wijst ook op het verlies van biodiversiteit (aantal soorten) en biomassa (omvang van soorten), bijvoorbeeld insecten. In het kader van de nationale veiligheid zijn dan vooral de effecten op de landbouw zorgwekkend. Tot slot gaat de scan in op de toegenomen milieudruk: menselijke activiteiten hebben negatieve gevolgen voor de bodem, water en luchtkwaliteit. Neem grondwaterbeheer: dat kan op korte termijn voordeel opleveren voor de landbouw, maar kan op langere termijn tot schade leiden in de vorm van o.a. verzilting. Concluderend heeft een aantal overkoepelende megatrends effect op meerdere thema's. Spanningen tussen grootmachten bijvoorbeeld, hebben een negatief effect op het vermogen van de internationale gemeenschap om samen te werken op allerlei thema's. Dit heeft gevolgen voor de financieel-economische orde, klimaatafspraken, terrorismebestrijding en kan tevens een effectieve aanpak van cyberen hybride dreigingen in de weg staan. Een ander voorbeeld is de rol van ICT. Naast de risico's van de onbeheersbaarheid van ICT en de toenemende afhankelijkheid ervan, zien we dat ICT ons kwetsbaar maakt voor systeemovername van buitenaf. In de volgende editie van de Horizonscan Nationale Veiligheid wordt meer aandacht besteed aan dergelijke 'overstijgende’ risico's.

\section{Tot slot}

Hierboven zijn het doel, de methode en belangrijkste uitkomsten van de Geïntegreerde risicoanalyse en de Horizonscan Nationale Veilig- 
heid besproken. De producten geven door het gebruik van een gestructureerde werkwijze inzicht in de risico's voor de nationale veiligheid en geven een beeld van wat er op langere termijn op ons afkomt. Beide producten maken tegenwoordig onderdeel uit een nieuwe strategische beleidscyclus, waardoor een constante monitoring van de relevante ontwikkelingen voor de nationale veiligheid geborgd wordt. Dat is een belangrijke verbetering ten opzichte van voorgaande jaren.

De belangrijkste uitdaging voor het Analistennetwerk Nationale Veiligheid in de toekomst is nog beter grip krijgen op de complexiteit en verwevenheid van de risico's voor de nationale veiligheid. Het ANV bewaakt daarom niet alleen de (methodologische) kwaliteit van zijn producten nauwgezet, maar is constant bezig deze te verbeteren en nieuwe producten te ontwikkelen. Voor de recente Geïntegreerde risicoanalyse is bijvoorbeeld een nieuw veiligheidsbelang met bijbehorende impactcriteria ontwikkeld: de 'internationale rechtsorde', dat nu onderdeel uitmaakt van het afwegingskader voor de nationale veiligheid. Ook zijn nieuwe criteria ontwikkeld met betrekking tot de aantasting van het bondgenootschappelijk grondgebied en de aantasting van de integriteit van de digitale ruimte. In de Horizonscan is het ANV ook voortdurend op zoek naar aanscherping van de methode en het product. In de nieuwste editie is er zoals gezegd meer aandacht voor integrale thema's: onderwerpen of risico's die terugkomen bij meerdere thema's. Op deze wijze zal het ANV met zijn analyses, die gebouwd zijn op de veelzijdigheid aan expertises binnen het netwerk, ook de komende jaren een bijdrage blijven leveren aan de nationale veiligheid.

\section{Literatuur}

ANV 2016

ANV, Nationaal veiligheidsprofiel, Bilthoven: RIVM, 2016.

\section{ANV 2018}

ANV, Horizonscan Nationale Veiligheid 2018. Analistennetwerk Nationale Veiligheid, Bilthoven: 2018.

\section{ANV 2019a}

ANV, Geïntegreerde risicoanalyse Nationale Veiligheid, Analistennetwerk Nationale Veiligheid, 2019. 


\section{ANV 2019b}

ANV, Leidraad risicobeoordeling Geïntegreerde risicoanalyse Nationale Veiligheid, Analistennetwerk Nationale Veiligheid, 2019.

\section{Instituut Clingendael 2018} Instituut Clingendael, General Method Global Security Pulse, Den Haag: Instituut Clingendael, 2018.

\section{OECD 2009}

OECD, Innovation in country risk management: a cross national analysis. OECD studies in risk management, www.oecd.org, 2009.

\section{OECD 2017}

OECD, National Risk Assessments: A Cross Country Perspective, Parijs: OECD Publishing, 2017, http://dx.doi.org/ 10.1787/9789264287532-en. 